\title{
LETTER
}

Epidemiology

\section{Reduction in the rate and improvement in the prognosis of COVID-19 in haematological patients over time}

\author{
Chiara Cattaneo $\mathbb{1}^{1} \cdot$ Chiara Pagani $^{1}$ - Valeria Cancelli ${ }^{1}$. Luisa Imberti ${ }^{2}$ - Aldo M. Roccaro ${ }^{3}$ - Luigi D. Notarangelo ${ }^{4}$. \\ Giuseppe Rossi ${ }^{1}$
}

Received: 27 June 2020 / Accepted: 30 July 2020 / Published online: 7 August 2020

(c) Springer Nature Limited 2020

\section{To the Editor:}

We read with interest the recommendations for clinicians caring for patients with malignant diseases in the COVID19 era proposed by the EHA Infectious Disease Scientific Working Group (IDSWG) [1]. Haematological patients are considered highly vulnerable to the recent COVID-19 pandemic. A very high fatality rate of $50-56 \%$ has been reported in 13 Chinese patients mainly affected by acute leukaemia and hospitalized during COVID pandemic [2], as well as in ten Italian patients with acute leukaemia [3]. Subsequently, several studies have confirmed that patients with different haematological malignancies have a significantly worse outcome compared to non-neoplastic patients, but also to patients with solid cancers upon SARS-CoV-2 infection [4-7]. Our department provides specialized haemato-oncologic care to the entire population of 1.2 million people living in the province of Brescia, Lombardy, in Northern Italy, one of the geographic areas most heavily plagued by COVID-19. During March 2020, in the first series of 90 patients affected by multiple types of haematological disorders, including non-neoplastic diseases, and diagnosed with symptomatic COVID-19 at our centre, a worrisome fatality rate of $40 \%$ was registered, consistent with what was observed at other centres [4-7].

Chiara Cattaneo

chiara.cattaneo@asst-spedalicivili.it

1 Department of Haematology, ASST Spedali Civili, Brescia, Italy

2 CREA Laboratory (AIL Center for Hemato-Oncologic Research), ASST Spedali Civili, Brescia, Italy

3 Clinical Research Development and Phase I Unit, ASST Spedali Civili, Brescia, Italy

4 Laboratory of Clinical Immunology and Microbiology, National Institute of Allergy and Infectious Diseases, NIAID, National Institutes of Health, NIH, Bethesda, MD, USA
The risk of death was independent from the nature of the underlying haematological disease; however, patients on active treatment had a worse prognosis than those not requiring treatment.

Given the paucity of knowledge about COVID-19 evolution, many investigators, government agencies and professional societies have drafted guidelines for patients with leukaemia and myeloid malignancies [8], as well as for oncological and transplant patients $[9,10]$. In general, it was suggested to limit unnecessary hospital visits and to balance the risk and benefit of administering potentially harmful treatment. As suggested, we have prioritized telehealth services and we have tried to defer or temporarily stop administration of cytostatic and immunosuppressive treatments, including consolidation treatments and transplants for patients in stable remission. The duration of treatment programmes has been shortened and maintenance treatments have been discontinued in responsive patients with indolent lymphoma. In addition, the fear of becoming infected during the pandemic has discouraged many patients from seeking in-hospital evaluation. Indeed, the number of patients with newly diagnosed haematological disease during the months of March and April 2020 dropped by $52 \%$ compared to the same period of 2019 . Also, the number of first evaluations for urgent haematological problems decreased from 202 during January and February to 80 during March and April 2020.

More recently, a significant decline in the number of new cases of COVID-19 has been observed in our region as well as in other countries. Since March 1st we have been collecting all cases of COVID-19 diagnosed by SARS-CoV-2 detection with reverse transcription-polymerase chain reaction-based assay on nasal and pharyngeal swab, occurring in haematological patients managed at our centre. As of June 2nd, a total of 137 patients with symptomatic SARSCoV-2 infection have been detected. We have noted that the number of COVID-19 cases significantly declined after March also in haematological patients. In addition, we 
Table 1 Clinical characteristics of the three monthly cohorts.

\begin{tabular}{|c|c|c|c|}
\hline Patients & $\begin{array}{l}\text { March 2020 } \\
(N=108)\end{array}$ & $\begin{array}{l}\text { April } 2020 \\
(N=26)\end{array}$ & $\begin{array}{l}\text { May } 2020 \\
(N=3)\end{array}$ \\
\hline Male sex & $71(66 \%)$ & $16(62 \%)$ & $3(100 \%)$ \\
\hline Median age (years) (range) & $71(31-94)$ & $71(20-86)$ & $60(35-70)$ \\
\hline \multicolumn{4}{|l|}{ Haematologic disease } \\
\hline Anaemia & $6(6 \%)$ & $0(-)$ & $1(33 \%)$ \\
\hline Thrombocytopenia & $2(2 \%)$ & $2(8 \%)$ & $0(-)$ \\
\hline $\begin{array}{l}\text { Indolent non-Hodgkin } \\
\text { lymphoma }\end{array}$ & $23(22 \%)$ & $4(15 \%)$ & $1(33 \%)$ \\
\hline $\begin{array}{l}\text { Aggressive non-Hodgkin } \\
\text { lymphoma }\end{array}$ & $22(20 \%)$ & $5(19 \%)$ & $0(-)$ \\
\hline Hodgkin lymphoma & $3(3 \%)$ & $1(4 \%)$ & $0(-)$ \\
\hline $\begin{array}{l}\text { Chronic lymphocytic } \\
\text { leukaemia }\end{array}$ & $15(14 \%)$ & $2(8 \%)$ & $0(-)$ \\
\hline Multiple myeloma & $18(17 \%)$ & $4(15 \%)$ & $1(33 \%)$ \\
\hline Acute leukaemia & $4(4 \%)$ & $1(4 \%)$ & $0(-)$ \\
\hline Myelodysplastic syndrome & $6(6 \%)$ & $1(4 \%)$ & $0(-)$ \\
\hline $\begin{array}{l}\text { MPN/chronic myeloid } \\
\text { leukaemia }\end{array}$ & $9(8 \%)$ & $6(23 \%)$ & $0(-)$ \\
\hline \multicolumn{4}{|l|}{ Haematologic disease status } \\
\hline Diagnosis & $18(17 \%)$ & $5(19 \%)$ & $1(33 \%)$ \\
\hline Remission & $42(39 \%)$ & $8(23 \%)$ & $0(-)$ \\
\hline Stable disease & $22(21 \%)$ & $8(31 \%)$ & $1(33 \%)$ \\
\hline Relapse/refractory & $26(24 \%)$ & $5(19 \%)$ & $1(33 \%)$ \\
\hline $\begin{array}{l}\text { Active chemo/ } \\
\text { immunosuppressive therapy }\end{array}$ & $57(53 \%)$ & $17(65 \%)$ & $2(67 \%)$ \\
\hline $\begin{array}{l}\text { Need of oxygen at COVID-19 } \\
\text { diagnosis }\end{array}$ & $60(56 \%)$ & $15(56 \%)$ & $0(-)$ \\
\hline
\end{tabular}

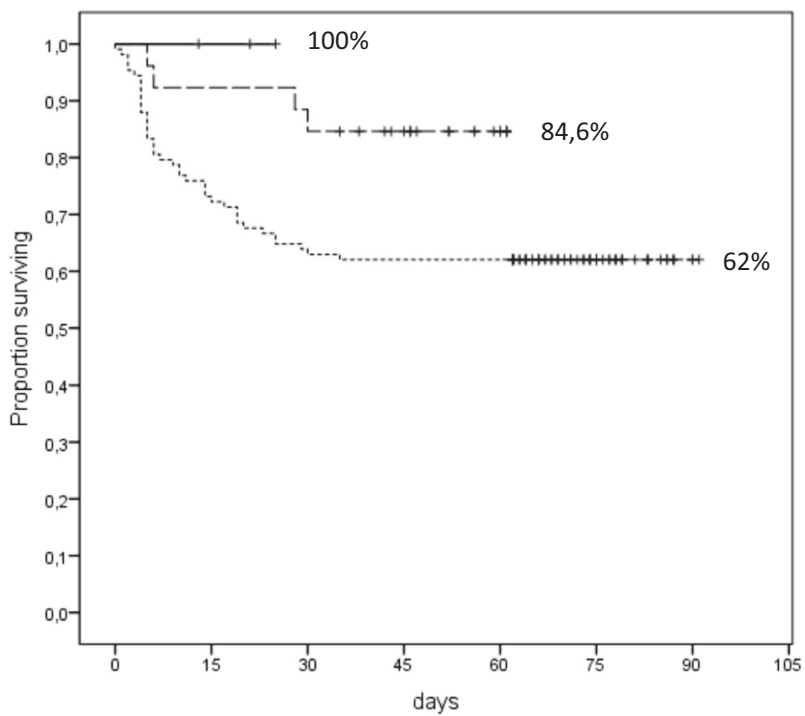

Fig. 1 Survival of the three cohorts as of June 2nd. Survival of patients after acute COVID-19 diagnosed in March (-...-...), April (----) or May 2020 (-), respectively. Survival duration was calculated from the date of SARS-CoV-2-positive swab. The difference of survival probability between patients diagnosed in March versus April 2020 is significant (log-rank test: $P=0.03$ ). realized that even the severity of COVID-19 was declining in parallel. Therefore, we have analysed the fatality rate within the three cohorts of patients diagnosed with COVID-19 in March, April and May 2020, respectively. Clinical characteristics of the three cohorts do not show significant differences regarding age, sex, haematological diagnosis and disease status, as well as the proportion of patients undergoing active haematological treatment (Table 1). Need of oxygen treatment was similar in March and April cohorts; it was absent in the three patients observed in May. All patients were managed in COVID-dedicated units with the same therapies and respiratory support measures also adopted for non-haematological patients throughout the entire period.

Out of 108 patients diagnosed in March, 40 (37\%) died after a median of 5.5 days. In April, a diagnosis of COVID19 was established in 26 patients, 4 of whom (19\%) died, after a median of 17 days. Of note, all fatalities occurred by April 5th. Only three patients were diagnosed with COVID19 in May, and none of them has died. Figure 1 shows the survival of the three cohorts as of June 2 nd.

These data would confirm that, in addition to a marked decrease in the number of patients infected, consistent with the global evolution of the pandemic, also the overall prognosis of COVID-19 has markedly improved. The survival of patients diagnosed in April versus March was significantly better, in spite of similar demographic and clinical features, including the need of oxygen supplementation at diagnosis. The fatality rate consistently reported by several authors during the peak of the pandemic has rapidly declined after March and has reached negligible levels after April 15th. There is much controversy about the potential causes of this phenomenon, including a reduction in viral inoculum or virulence, or as yet unrecognized causes.

Nonetheless, should similar data be reported also by others, the criteria proposed for the management of haematological patients during COVID-19 may need to be revised in order to more properly balance the risk of COVID-19 with that of undertreating severe, potentially life-threatening haematological disorders. Moreover, with the reduction of pandemic burden, patients should also be encouraged to seek in-hospital evaluation in the presence of haematological abnormalities, since the risk of underestimating severe clinical problems may become actually higher than the risk of acquiring symptomatic COVID-19.

Acknowledgements L.D.N. is supported by the Division of Intramural Research Programme, National Institute of Allergy and Infectious Diseases, National Institutes of Health.

\section{Compliance with ethical standards}

Conflict of interest L.I. has received speaker honoraria from Biogen, Genzyme-Sanofi, Meck-Serono and Novartis, has participated to 
scientific advisory board for Biogen and has received research funding from FISM Fondazione Italiana Sclerosi Multipla) and research support from Genzyme-Sanofi; A.M.R. reports grants from Associazione Italiana per la Ricerca sul Cancro, European Haematology Association, Fondazione Regionale per la Ricerca Biomedica, ERA-NET TRANSCAN-2, AstraZeneca, and other grants from Amgen, Celgene and Janssen, outside the submitted work; G.R. reports personal fees outside the submitted work from Celgene, Abbvie, Janssen, Jazz, Astellas, Daichii-Sankyo, Amgen and Roche Pfizer. All other authors declare no conflict of interest.

Publisher's note Springer Nature remains neutral with regard to jurisdictional claims in published maps and institutional affiliations.

\section{References}

1. von Lilienfeld-Toal M, Vehreschild JJ, Cornely O, Pagano L, Compagno F, Hirsch HH.EHA Infectious Disease Scientific Working Group Frequently asked questions regarding SARS-CoV-2 in cancer patients - recommendations for clinicians caring for patients with malignant diseases. Version 2. Leukemia. 2020;34:1487-94. https://doi.org/10.1038/s41375-020-0832-y.

2. He W, Chen L, Chen L, Yuan G, Fang Y, Chen W. et al. COVID19 in persons with haematological cancers. COVID-19 in persons with haematological cancers. Leukemia. 2020; https://doi.org/10. 1038/s41375-020-0836-7.

3. Ferrara F, Zappasodi P, Roncoroni E, Borlenghi E, Rossi G. Impact of Covid-19 on the treatment of acute myeloid leukemia. Leukemia. 2020; https://doi.org/10.1038/s41375-020-0925-7.

4. Mehta V, Goel S, Kabarriti R, Cole D, Goldfinger M, AcunaVillaorduna A, et al. Case fatality rate of cancer patients with
COVID-19 in a New York Hospital System. Cancer Discov. 2020. https://doi.org/10.1158/2159-8290.

5. Malard F, Genthon A, Brissot E, van de Wyngaert Z, Marjanovic Z, Ikhlef S, et al. COVID-19 outcomes in patients with haematological disease. Bone Marrow Transplant. 2020. https://doi.org/ 10.1038/s41409-020-0931-4.

6. Martín-Moro F, Marquet J, Piris M, Michael BM, Sáez AJ, Corona M, et al. Survival study of hospitalized patients with concurrent Covid-19 and haematological malignancies. $\mathrm{Br} \mathrm{J}$ Haematol. 2020. https://doi.org/10.1111/bjh.16801.

7. Shah V, Ko Ko T, Zuckerman M, Vidler J, Sharif S, Mehra V, et al. Poor outcome and prolonged persistence of SARS-CoV-2 RNA in COVID-19 patients with haematological malignancies; King's College Hospital experience. Br J Haematol. 2020. https://doi.org/10.1111/bjh.16935.

8. Zeidan AM, Boddu PC, Patnaik MM, Bewersdorf JP, Stahl M, Rampal RK, et al. Special considerations in the management of adult patients with acute leukaemias and myeloid neoplasms in the COVID-19 Era: recommendations from a panel of international experts. Lancet Haematol. 2020. https://doi.org/10.1016/S23523026(20)30205-2.

9. Mauri D, Kamposioras K, Tolia M, Alongi F, Tzachanis D, International Oncology Panel and European Cancer Patient Coalition collaborators. Summary of international recommendations in 23 languages for patients with cancer during the COVID-19 pandemic. Lancet Oncol. 2020;21:759-60.

10. Ljungman P, Mikulska M, de la Camara R, Basak GW, Chabannon C, Corbacioglu S, et al. European Society for Blood and Marrow Transplantation. The challenge of COVID-19 and hematopoietic cell transplantation; EBMT recommendations for management of hematopoietic cell transplant recipients, their donors, and patients undergoing CAR T-cell therapy]. Bone Marrow Transplant. 2020. https://doi.org/10.1038/s41409-020-0919-0. 